\title{
Las proteínas del plasma seminal incrementan la viabilidad espermática post-descongelación del semen de toros Sanmartinero
}

\section{Seminal plasma proteins increase the post-thaw sperm viability of Sanmartinero bull's semen}

\author{
Fabián Rueda A, ${ }^{1}$ Lic Quím, Tatiana Garcés P, ${ }^{2}$ Biól, Rocío Herrera $L_{,}{ }^{1}$ Zootec, \\ Luis Arbeláez R, ${ }^{2}$ Ph.D, Miguel Peña J, ${ }^{3}$ MVZ, Henry Velásquez P, ${ }^{3}$ M.Sc, \\ Aureliano Hernández V, ${ }^{4}$ Ph.D, Jaime Cardozo C, ${ }^{1 *}$ Ph.D.
}

\begin{abstract}
${ }^{1}$ Corporación Colombiana de Investigación Agropecuaria CORPOICA. Centro de Biotecnología y Bioindustria. Laboratorio de Microbiología Molecular. Cundinamarca, Colombia. ${ }^{2}$ Universidad de Pamplona. Laboratorio del Grupo de Investigación en Química. Ciudad universitaria. Pamplona, Norte de Santander, Colombia. ${ }^{3}$ CORPOICA. Centro de Reproducción Integral Animal (CRIA). Centro de Investigación La Libertad. Km 21 vía Pto. López, Villavicencio, Colombia. ${ }^{4}$ Universidad Nacional de Colombia. Facultad de Medicina Veterinaria y de Zootecnia. Bogotá, Colombia. *Correspondencia: jcardozo@corpoica.org.co
\end{abstract}

Recibido: Mayo de 2011; Aceptado: Enero de 2012.

\section{RESUMEN}

Objetivo. El objetivo de este trabajo fue evaluar el efecto de la adición de proteínas del plasma seminal sobre el porcentaje de espermatozoides bovinos viables post-descongelación. Materiales y métodos. Los espermatozoides se congelaron usando dos medios (citrato-fructosa-yema y Bioxcell ${ }^{\circledR}$ ) y la obtención de proteínas de plasma seminal de bajo peso molecular se realizó por medio de cromatografía líquida de baja presión. Las proteínas de interés eluyeron en las fracciones $21-25$ y se sometieron a electroforésis en una y dos dimensiones. Los espermatozoides se incubaron a $37^{\circ} \mathrm{C}$ durante una hora, con $0.5,1.0,1.5$ y $2.0 \mathrm{mg}$ de la fracción $21-25$. Se incluyeron dos tratamientos adicionales: uno con proteínas totales del plasma seminal y otro sin proteína. Resultados. La electroforésis bidimensional de las fracciones confirmó la presencia de siete puntos de proteína de bajo peso molecular (14-16 kDa y punto Isoeléctrico de 5.0 - 5.5). La adición de estas proteínas aumentó $20 \%(p<0.05)$, el porcentaje de espermatozoides viables post-descongelación en muestras congeladas en medio citrato-fructosayema (con dosis de 1 ó $1.5 \mathrm{mg}$ de proteína/106 espermatozoides), y $25 \%(p<0.05)$ en muestras congeladas en medio Bioxcell ${ }^{\circledR}$ (con dosis de $0.5 \mathrm{mg}$ de proteína $/ 10^{6}$ espermatozoides). Conclusiones. Los resultados de esta investigación sugieren el posible uso de proteínas de bajo peso molecular del plasma seminal, para disminuir el efecto deletéreo de la criopreservación en los espermatozoides.

Palabras clave: Capacitación espermática, criopreservación, espermatozoide, plasma seminal, proteínas de choque térmico (Fuente: DeCS). 


\section{ABSTRACT}

Objectives. This study was performed to evaluate the effect of the addition of proteins on the postthawing viability of spermatozoa. Materials and methods. Spermatozoa were frozen with two different media: Citrate-fructose and Bioxcell ${ }^{\circledR}$. The isolation of seminal plasma proteins of low molecular weight was performed through low pressure liquid chromatography. It was determined that the proteins of interest eluted in fractions 21-25, and two dimensional electrophoresis was performed. Thawed sperm was incubated at $37^{\circ} \mathrm{C}$ for one hour with $0.5,1,1.5$ and $2.0 \mathrm{mg}$ of $21-25$ fraction protein. Two additional treatments were included: one with seminal plasma total protein, and another one without protein. Results. Two dimensional electrophoresis of protein confirmed the presence of two bands of 14 and $16 \mathrm{kDa}$ and seven spots with iso-electric points between 5.0 - 5.5 respectively. Incubation of the spermatozoa with the 21-25 fraction showed that sperm viability increases by $20 \%$ with doses of 1 and $1.5 \mathrm{mg}$ of protein/106 spermatozoa in the citrate-fructose medium, and $25 \%$ with $0.5 \mathrm{mg}$ of protein/106 spermatozoa in Bioxcell ${ }^{\circledR}$ medium. A positive effect in sperm viability was demonstrated although it depends on the doses of protein and the cryopreservation medium used. Conclusions. This investigation suggests that the use of seminal plasma proteins can be useful for reducing the harmful effect on sperm cryopreservation.

Key words: Cryopreservation, heat shock proteins, seminal plasma, sperm capacitation, sperm (Source: DeCS).

\section{INTRODUCCION}

El plasma seminal (PS) es una mezcla de secreciones de diferentes partes del aparato reproductor masculino. Componentes del PS como carbohidratos, lípidos, proteínas y minerales, influyen en la capacidad fecundante de los espermatozoides (spz). El estudio de las funciones de las proteínas del PS, ha permitido su uso en el proceso de criopreservación, con el fin de incrementar la viabilidad espermática post-descongelación $(1,2)$.

Durante la criopreservación, la distribución de fosfolípidos y proteínas en la membrana plasmática se altera y provoca una capacitación prematura del $\mathrm{spz}$, disminuyendo su viabilidad. Los estudios revelan que los cambios de temperatura afectan la integridad de las células en niveles estructurales por la rotura mecánica de la membrana y por la redistribución de los fosfolípidos en la misma $(3,4)$.

Estos daños se han intentado disminuir mediante el uso de diferentes crio-protectores. El más empleado ha sido la yema de huevo por su contenido de lipoproteínas de baja densidad (LDL), la cual es la responsable del efecto crioprotector $(5,6)$. Sin embargo, el uso de yema de huevo puede incrementar el riesgo de contaminación microbiana y reducir la capacidad fecundante de los spz. En vista de lo anterior, se ha propuesto el uso de diluyentes que no contengan yema de huevo, como el caso de aquellos a base de lecitina de soya. El uso de estos diluyentes ha evidenciado incrementos importantes en la viabilidad post-descongelación en semen bovino $(7,8)$.

Se ha descrito un grupo de proteínas ácidas del PS de bajo peso molecular (13-16 kDa), las cuales se adsorben a la membrana plasmática del spz y desempeñan un papel crucial en la regulación de la capacitación $(9,10)$. Estas proteínas, son secretadas por las vesículas seminales (11-13), y se han empleado para proteger al spz contra el estrés térmico y oxidativo $(14,15)$. Igualmente, se ha demostrado que la incubación de spz in vitro con proteínas de PS, puede contrarrestar los daños ocasionados a las células espermáticas sometidas a choques térmicos $(1,13)$.

Pérez-pé et al en 2000 (14), y Colás et al en 2009 (15), demostraron que una fracción de proteínas de bajo peso molecular del PS ovino, podía restaurar la estructura de la membrana de forma cercana a las células intactas en spz sometidos a choque térmico por frío.

Según lo anterior, es posible que el uso de aditivos basados en proteínas del PS, logre revertir parcialmente los daños causados por los procesos de criopreservación en Spz de toros. El objetivo del presente estudio fue estimar el efecto de la incubación de spz de toros Sanmartinero, con proteínas de bajo peso molecular del PS, aisladas por cromatografía de exclusión, sobre el porcentaje de spz viables post-descongelación. 


\section{MATERIALES Y MÉTODOS}

Sitio de estudio y unidades experimentales. Esta investigación se realizó con semen congelado de 10 toros de la raza criolla Sanmartinero, usando 3 pajillas de cada toro. Los animales, de entre 3 y 4 años de edad, permanecieron en el centro de investigación La Libertad de CORPOICA en condiciones adecuadas de salud, bajo pastoreo en praderas de Brachiaria decumbens.

El semen se colectó por electroeyaculación y se determinaron los parámetros convencionales de calidad seminal: viabilidad (integridad de la membrana), motilidad y concentración espermática al momento de la eyaculación. Esta última se determinó con un Spermacue Minitube ${ }^{\circledR}$. La viabilidad espermática se determinó mediante recuento de spz con tinción diferencial Carboxifluoresceína-ioduro de propidio (16), para lo cual la muestra de semen descongelado se diluyó en mHTF $(1: 35)$, posteriormente se le adicionó $5 \mu \mathrm{l}$ de diacetato de carboxifluoresceína (10 $\mu \mathrm{M}$ en agua destilada), $5 \mu \mathrm{l}$ de ioduro de propidio ( $7.3 \mu \mathrm{M}$ en DMSO) y $5 \mu$ lde formaldehído $1.7 \mathrm{mM}$, para inmovilizar las células con objeto de lograr una mejor observación. La muestra se incubó a $37^{\circ} \mathrm{C}$ durante 15 minutos, al cabo de los cuales se colocaron $8 \mu$ l de la muestra sobre una lámina portaobjeto. Se contaron 200 células por alícuota con un objetivo $40 x$ en un microscopio con iluminación epifluorescente, la viabilidad se determinó como se mencionó anteriormente en la cual los spz con membrana íntegra toman un color verde y los que presentan daño, un color rojo. La motilidad individual se determinó por análisis visual de una alícuota de $8 \mu$ bajo un microscopio óptico con objetivo de 40x, teniendo en cuenta sólo los spz con movimiento progresivo en varios campos ópticos.

Criopreservación del semen. La criopreservación se realizó con dos diluyentes diferentes: Citrato-fructosa con yema de huevo (CFY) y un medio comercial para congelación (Bioxcell ${ }^{\circledR}$, IMV Francia). El medio de criopreservación CFY se preparó usando citrato de sodio $29 \mathrm{~g} / \mathrm{L}$, fructosa $12.5 \mathrm{~g} / \mathrm{L}$, penicilina $100 \mathrm{UI} / \mathrm{ml}, 1 \mathrm{mg}$ de estreptomicina y yema de huevo $20 \%$ (fracción A del diluyente), mientras la fracción B se preparó con $86 \%$ de la fracción A y $14 \%$ de glicerol.

La disminución de la temperatura de la muestra seminal en el medio crioprotector se hizo de forma progresiva de 37 a $5^{\circ} \mathrm{C}$ a razón de $0.5^{\circ} \mathrm{C}$ por minuto aproximadamente. Alcanzada la temperatura de $5^{\circ} \mathrm{C}$, se adicionó la fracción $\mathrm{B}$ (en la misma cantidad de la mezcla entre la fracción A y semen), y se mantuvo el semen a esta temperatura durante 4-6 horas. La congelación con el medio comercial Bioxcell ${ }^{\circledR}$ se realizó de la misma forma que con el medio citrato-fructosa, reemplazando las fracciones A y $B$ por las 1 y 2 del Bioxcell ${ }^{\circledR}$. El semen se llevó a una concentración de $70 \times 10^{6} \mathrm{spz}$ por $\mathrm{ml}$, se empacó en pajillas de $0.5 \mathrm{ml}$, las cuales se sellaron por ultrasonido y se llevaron a vapores de nitrógeno líquido durante $10 \mathrm{~min}$ hasta alcanzar $-120^{\circ} \mathrm{C}$. Posteriormente el semen se introdujo en nitrógeno líquido para alcanzar una temperatura de $-196^{\circ} \mathrm{C}$. Sólo se usaron las pajillas con motilidad individual progresiva postdescongelación $\geq 40 \%$, después de 48 horas.

Colección de PS y cuantificación de proteínas. EI PS se obtuvo por centrifugación del semen a $10.500 \times \mathrm{g}$ durante $5 \mathrm{~min}$ a $4^{\circ} \mathrm{C}$ dos veces sucesivas. El sobrenadante obtenido se filtró mediante una membrana Millipore $6 \mathrm{~V}$ de $0.22 \mu \mathrm{m}$. Al filtrado se le adicionó fenilmetilsulfonil fluoruro (PMSF) $5 \mu \mathrm{M}(1.0 \mu \mathrm{l}$ por cada $\mathrm{ml}$ de PS) disuelto en dimetilsulfoxido (DMSO), como agente inhibidor de serinoproteasas y se guardó a $-20^{\circ} \mathrm{C}$ hasta su uso. Posteriormente se realizó la cuantificación de proteínas de las muestras de PS mediante espectrofotometría $A_{280}$. Se usó el coeficiente de absortividad molar $\left(\varepsilon^{1 \%}=6.67 \mathrm{M}^{-1} \mathrm{~cm}^{-1}\right)$ de la albúmina sérica bovina BSA.

Separación de fracciones proteícas por cromatografía de exclusión por tamaño. Las proteínas del PS fueron separadas por cromatografía de exclusión, en el Laboratorio del Grupo de Investigación en Química de la Facultad de Ciencias Básicas, de la Universidad de Pamplona. Para esta separación se utilizó el cromatógrafo BioLogic de Bio-rad y una columna de $1 \times 120 \mathrm{~cm}$, con $79 \mathrm{ml}$ de Sephacryl S-200 HR (Amersham Biosciences) como fase estacionaria, que se lavó previamente con $100 \mathrm{ml}$ de $\mathrm{NaOH}$ $0.1 \mathrm{M}$ y 2 litros de agua destilada. La matriz se equilibró con tampón fosfato $0.05 \mathrm{M}, \mathrm{pH} 8.0$ a una velocidad de $0.25 \mathrm{ml} / \mathrm{min}$. Se aplicó $1 \mathrm{ml}$ de PS (170 mg de proteína), posteriormente se eluyó con $200 \mathrm{ml}$ de la misma solución tampón y a la misma velocidad que la de equilibrio, y se recogieron fracciones de $4 \mathrm{ml}$ por tubo. En cada tubo se determinó la concentración de proteínas espectrofotométricamente a $A_{280} \mathrm{~nm}$, empleando el coeficiente de absorción molar de 0.667 . Los picos obtenidos fueron colectados y concentrados a través de una celda de ultrafiltración Amicon (Millipore). Una vez concentrados, se filtraron de nuevo en microfiltros de $3 \mathrm{kDa}$ para eliminar las sales y se sometieron a liofilización durante 24 horas, luego de las cuales se almacenaron a $-20^{\circ} \mathrm{C}$ hasta su uso. 
Electroforesis unidimensional (SDS-PAGE). Las fracciones de proteínas obtenidas por cromatografía, se sometieron a electroforésis en geles de poliacrilamida con dodecilsulfato de sodio (SDS-PAGE), de acuerdo con el método de Laemmli (17). Los geles se elaboraron a una concentración de poliacrilamida del $15 \%$; Se utilizaron $5 \mu \mathrm{g}$ de proteína de las fracciones 21-25, y se diluyeron $1: 1(\mathrm{v} / \mathrm{v})$ con la solución tampón de muestra (20\% Glicerol, 2\% SDS, $0.5 \mathrm{M}$ Tris- $\mathrm{HCl} \mathrm{pH} \mathrm{6.8,10 \%} \beta$-mercaptoetanol, $y$ $0.05 \%$ de azul de bromofenol). Las muestras se desnaturalizaron incubando 5 minutos a $100^{\circ} \mathrm{C}$ y la electroforesis se realizó a $250 \mathrm{~V}, 0.04 \Omega$. . Las bandas se visualizaron por tinción con Azul brillante de Comassie.

Electroforesis bidimensional (2D PAGE). Las fracciones (21-25) con proteínas del PS de bajo peso molecular, se sometieron a electroforésis bidimensional. La separación electroforética se llevó a cabo primero por puntos isoeléctricos, en una cámara de isoelectroenfoque IEF protean de Bio Rad, utilizando tiras de poliacrilamida en gradientes de $\mathrm{pH}$ inmovilizado (IPGs) de $8 \mathrm{~cm}$ de largo, y un rango de $\mathrm{pH}$ de 4 a 7 . Las tiras se hidrataron de forma pasiva (toda la noche) para lo cual se adicionaron $100 \mu \mathrm{g}$ de proteína total a una solución tampón compuesta por Urea $8 \mathrm{M}$, CHAPS 4\% p/v, Ditiotreitol (DTT) $50 \mathrm{mM}$ y anfolitos $2 \% \mathrm{v} / \mathrm{v}$, al que se adicionó $2 \mu \mathrm{lde}$ tributilfosfina (TBP) y $0.75 \mu \mathrm{l}$ de anfolitos en el momento de colocar la tira.

Las tiras enfocadas se sometieron a equilibrio en dos pasos, cada uno de $15 \mathrm{~min}$. En el primer paso se sumergieron en un tampón con urea $6 \mathrm{M}$, Tris 0.375 M, pH 8.8, SDS $2 \%$, glicerol $20 \%$, DTT $2 \%$ $(\mathrm{w} / \mathrm{v})$, $\mathrm{y}$ en el segundo paso se sumergieron en un tampón que difiere del primero en la sustitución de DTT por Iodoacetamida $2.5 \%(\mathrm{w} / \mathrm{v})$.

La segunda dimensión se realizó en minigeles de poliacrilamida en gradiente de concentración lineal de $10 \%$ a $20 \%$. Las tiras se fijaron a los geles mediante agarosa al $1 \%$ y azul de bromofenol a $2 \%$. La separación por peso molecular se realizó en una cámara de electroforesis Miniprotean cell de $\mathrm{Bio} \mathrm{Rad}^{\circledR}$ a 85 voltios durante $180 \mathrm{~min}$. La visualización de los puntos de proteína se efectuó de la misma manera que los geles en una dimensión.

Documentación de los geles y análisis de imágenes. Todos los geles se digitalizaron en un documentador Gel Doc XR (Bio $\left.\operatorname{Rad}^{\circledR}\right)$. El análisis de las imágenes de los geles en una dimensión se realizó con el programa Quantity One (Bio $\operatorname{Rad}^{\circledR}$ ) y los geles en dos dimensiones con el programa PD Quest (Bio $\operatorname{Rad}^{\circledR}$ ).
Adición de las proteínas separadas por cromatografía al semen descongelado. Para evaluar el efecto de la adición de proteínas de bajo peso molecular, en el porcentaje de spz viables post-descongelación, de cada pajilla se separaron alícuotas de un millón de spz y se asignaron a uno de los siguientes tratamientos: T1 (control negativo sin adición de proteínas), T2 (1.0 mg de proteínas totales del PS, control positivo) y las siguientes con distintas cantidades del concentrado de proteínas obtenido de las fracciones 21-25 resuspendidas en Human Tubular Fluid médium (mHTF): T3 (0.5 mg), T4 (1.0 mg), T5 (1.5 mg), T6 (2.0 $\mathrm{mg}$ ). Todas las muestras se incubaron a $37^{\circ} \mathrm{C}$ durante 1 hora. Finalizada la incubación, se determinó la viabilidad espermática mediante el método del ioduro de propidio-diacetato de carboxifluoresceína (16). El incremento porcentual en la viabilidad espermática por efecto de la incubación con proteínas, se determinó con respecto al control negativo.

El efecto de la adición de proteínas del PS en la reversión del daño de la membrana espermática, se estimó por la fórmula desarrollada por Barrios et al (1):

$\%$ reversión $=\frac{(V p 60-V c 60)}{(V w-V c 60)} \times 100$

Donde:

$\mathrm{V}_{\mathrm{w}}=$ viabilidad de la muestra fresca antes de la congelación

$\mathrm{V}_{\mathrm{c} 60}=$ viabilidad de la muestra control al cabo de una hora

$\mathrm{V}_{\mathrm{p} 60}=$ viabilidad de la muestra con proteínas al cabo de una hora

Este porcentaje representa la relación entre las células con viabilidad recuperada y las teóricamente recuperables.

Análisis estadístico. Se empleó un diseño completamente al azar con arreglo factorial $(4 \times 2)$ para el análisis de los datos, de acuerdo con el siguiente modelo:

$$
Y_{i j}=\mu+a_{i}+\beta_{j}+\left(a_{i} \beta j\right)+E_{i j}
$$

Donde:

$Y_{i j}=$ Porcentaje de recuperación de la viabilidad en las pajillas descongeladas

$\mu=$ Media total

$\mathrm{a}_{\mathrm{i}:}=$ Efecto de la dosis de fracción 21-25 obtenida

por exclusión

$\beta_{j}=$ Efecto del medio de criopreservación

$\left(\right.$ ai $\beta_{\mathrm{j}}$ ) = Efecto de la interacción

$\mathrm{E}_{\mathrm{ij}}=$ Error experimental 
Adicionalmente se realizó un análisis de varianza para determinar el efecto de los tratamientos y una prueba de comparación LS MEANS para evaluar las diferencias en el porcentaje de reversión del daño ocasionado por la criopreservación en la membrana espermática.

\section{RESULTADOS}

Separación parcial de las proteínas del plasma seminal por cromatografía de exclusión y electroforesis Uni-Bidimensional En el cromatograma de exclusión (Figura 1), se visualizan 2 picos, el primero constituido por el contenido de los tubos 10 al 20 (que se denominarán fracciones) y el segundo de los tubos 21 al 25. Se valoraron midiendo la concentración de proteínas a una longitud de onda de $280 \mathrm{~nm}$, utilizando un coeficiente de absorción de $6.67 \mathrm{M}^{-1} / \mathrm{cm}^{-1}$.
El contenido proteico de cada uno de los tubos que se encuentran en estos picos se analizó electroforéticamente por medio de SDS-PAGE al $15 \%$ (Figura 2), para identificar las bandas de proteínas contenidas en cada fracción. Desde la fracción F10 hasta la F25, se identificaron proteínas de pesos moleculares, entre 12 y $72 \mathrm{kDa}$. El concentrado de las fracciones 2125 fue identificado como la fracción donde se encuentran las proteínas de bajo peso molecular (entre 14 y $16 \mathrm{kDa}$ ) (Figura 2).

Este concentrado de proteínas se sometió a electroforésis bidimensional en rango de $\mathrm{pH}$ de 4 a 7. Se evidenció la presencia de 2 puntos en la banda de 14 y 5 puntos en la de $16 \mathrm{kDa}$ (Figura 3) lo que podría indicar que ambas bandas comprenden proteínas con diferencias post-traduccionales, como ya se ha descrito en ovino $(13,18)$

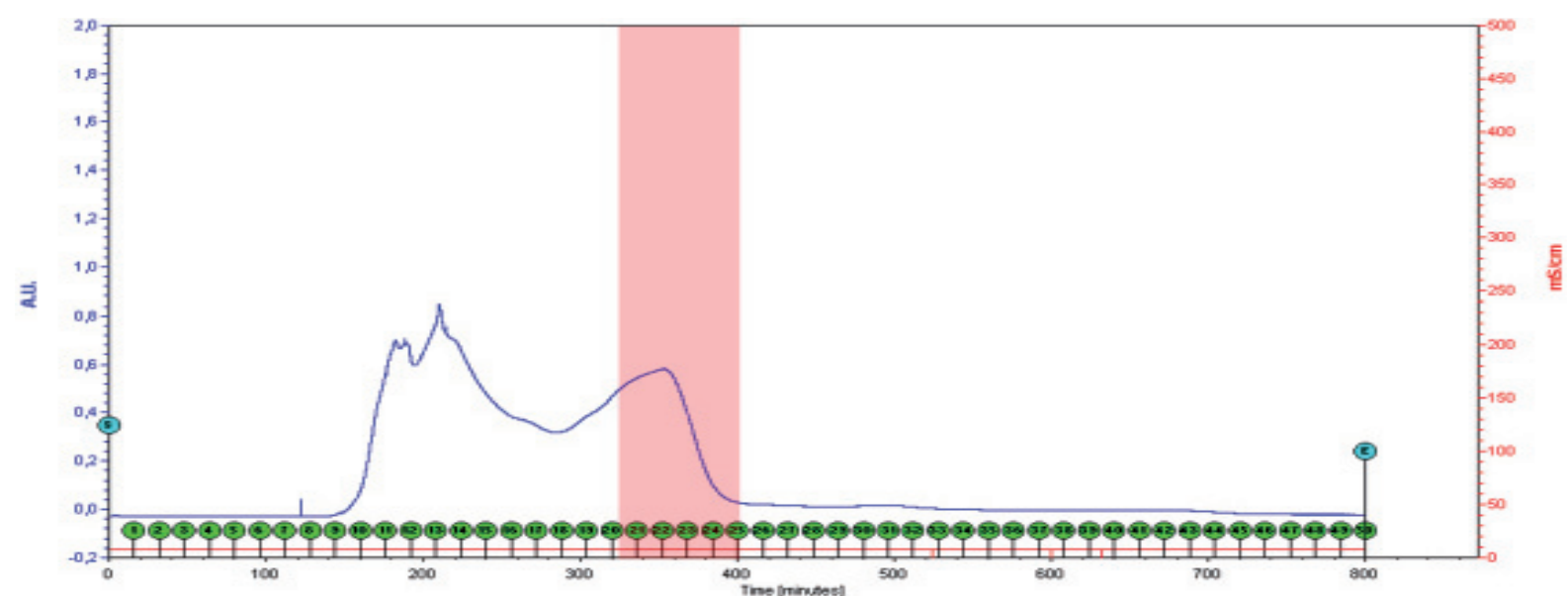

Figura 1. Fraccionamiento de proteínas del plasma seminal mediante cromatografía de exclusión por tamaño. Se señala el pico que comprende las fracciones 21 a 25

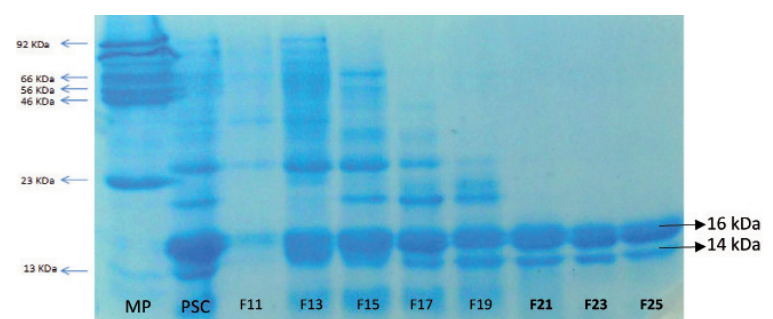

Figura 2. SDS-PAGE de las proteínas obtenidas en las fracciones separadas mediante cromatografía de exclusión por tamaño. Carril 1: Marcador de peso molecular (MP), Carril 2: Plasma seminal completo (PSC), Carril 3: Fracción 11, Carril 4: Fracción 13, Carriles 5 a 7: fracciones 15, 17 y 19, Carril 8: fracción 21 y Carriles 9 y 10: fracciones 23 y 25 . Los últimos tres carriles constituyen las proteínas de 14 a $16 \mathrm{kDa}$, de interés en este trabajo.

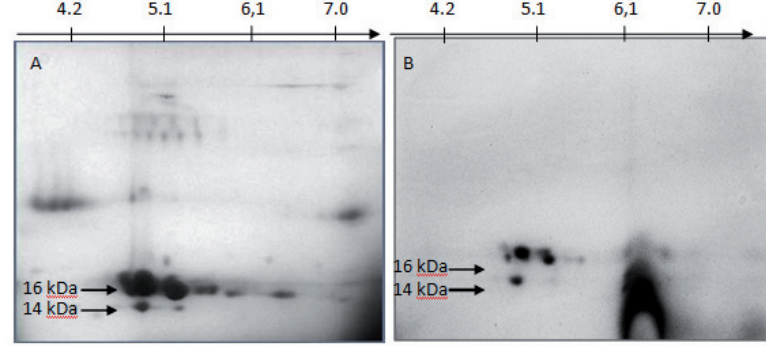

Figura 3. Electroforésis bidimensional de proteínas del PS de Sanmartinero con rango de separación de pH 4a 7. A. Gel bidimensional de plasma seminal completo. B. Gel bidimensional de la fracción 21-25, se señalan los 7 puntos presentes en las bandas de 14 y $16 \mathrm{kDa}$ 
Efecto de la incubación de los espermatozoides con la fracción 21 a 25 obtenida por cromatografía de exclusión. La adición de la fracción 21-25, evidenció efectos que difieren de acuerdo con la dosis y al medio de criopreservación empleados. El porcentaje de spz viables postincubación, en el tratamiento control sin proteínas adicionadas fue de $39.8 \pm 8.2 \%$, a partir del cual se calculó el incremento en viabilidad en los demás tratamientos. El mayor porcentaje de incremento en la viabilidad post-incubación fue $22.0 \pm 6.5 \%(p<0.05)$ y se consiguió con dosis de 1.0 y $1.5 \mathrm{mg} \mathrm{mg} / 10^{6} \mathrm{spz}$, de la fracción proteica en estudio, cuando los espermatozoides se criopreservaron con medio CFY (Figura 4).

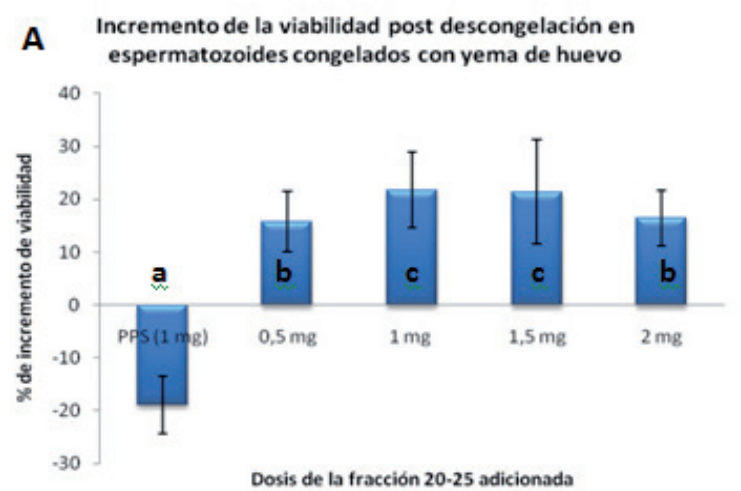

B Incremento de la viabilidad post descongelación en espermatozoides congelados con Bioxcell

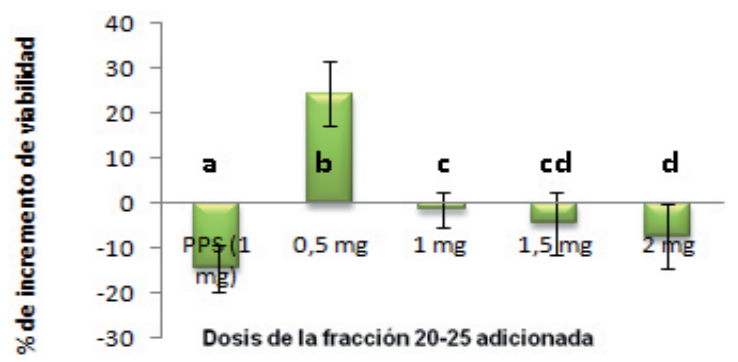

Figura 4. Incremento porcentual de la viabilidad postdescongelación de 106 espermatozoides criopreservados con: A) yema de huevo (CFY) y B) Bioxcell ${ }^{\circledR}$ comercial. El incremento se calculó teniendo como base la viabilidad del control (mHTF sin proteínas). Los espermatozoides se descongelaron e incubaron durante 1 hora a $37 \mathrm{C}^{\circ}$ con $1 \mathrm{mg}$ de proteínas totales del plasma seminal (PPS) y diferentes concentraciones de proteínas contenidas en la fracción 21-25.

Por otra parte, el incremento en el porcentaje de spz viables post incubación fue mayor $(25.2 \pm 5.3 \% \mathrm{p}<0.05)$ a una dosis de $0.5 \mathrm{mg} / 10^{6}$ spz., cuando los spz se criopreservaron en el medio comercial Bioxcell ${ }^{\circledR}$. Sin embargo, cuando se utilizaron dosis superiores a $0.5 \mathrm{mg} / 10^{6} \mathrm{spz}$ (entre 1.0 y $2.0 \mathrm{mg} / 10^{6} \mathrm{spz}$ ) se evidenció una disminución significativa $(p<0.05)$ de la viabilidad espermática postincubación (Figura 4).

La viabilidad espermática de las muestras frescas, medida a través de la tinción carboxifluoresceinaioduro de propidio, fue en promedio de $70.7 \pm 6.1 \%$, superior a la viabilidad postdescongelación promedio de todas las pajillas la cual fue de $28.0 \pm 5.2 \%$ (Tabla 1 ).

Tabla 1. Porcentaje de viabilidad espermática en semen fresco y post-descongelación con medio Bioxcell ${ }^{\circledR}$, e incubado con $1 \mathrm{mg}$ de proteínas totales (PT) y diferentes dosis de la fracción 21-25

\begin{tabular}{|c|c|c|c|c|c|c|}
\hline \multirow[b]{2}{*}{$\begin{array}{l}\text { Semen } \\
\text { fresco }\end{array}$} & \multirow[b]{2}{*}{$\begin{array}{l}\text { (mHTF sin } \\
\text { proteínas) }\end{array}$} & \multirow[b]{2}{*}{$\begin{array}{c}1 \mathrm{mg} \\
\text { PT del } \\
\text { PS }\end{array}$} & \multicolumn{2}{|c|}{ Viabilidad (\%) } & \multirow[b]{2}{*}{$\begin{array}{c}1.5 \\
\mathrm{mg} / 10^{6}\end{array}$} & \multirow[b]{2}{*}{$\underset{\mathrm{mp} / 10^{6}}{2}$} \\
\hline & & & $\begin{array}{c}0.5 \\
\mathrm{mg} / 10^{6} \\
\mathrm{spz}\end{array}$ & $\underset{\mathrm{spz}}{\stackrel{1}{\mathrm{mg} / 10^{6}}}$ & & \\
\hline 70.70 & $27.91^{b}$ & $19.94^{\mathrm{e}}$ & $32.32^{\mathrm{a}}$ & $25.73^{\mathrm{bc}}$ & $23.51^{\mathrm{cd}}$ & $22.20 \mathrm{de}^{\mathrm{e}}$ \\
\hline \pm 6.13 & \pm 5.16 & \pm 5.66 & \pm 6.55 & \pm 6.32 & \pm 6.38 & \pm 6.69 \\
\hline
\end{tabular}

Cuando los valores de incremento porcentual de la viabilidad espermática, se incluyeron en la fórmula propuesta por Barrios et al (1) para estimar el \% de recuperación de la viabilidad de los espermatozoides, se evidenció que el único tratamiento que tuvo un claro efecto de reversión del daño por criopreservación es aquel que empleó una dosis de $0.5 \mathrm{mg} / 10^{6} \mathrm{spz}(15.23 \%$, $\mathrm{p}<0.05$ ), en espermatozoides congelados con el medio comercial Bioxcell ${ }^{\circledR}$ (Figura 5).

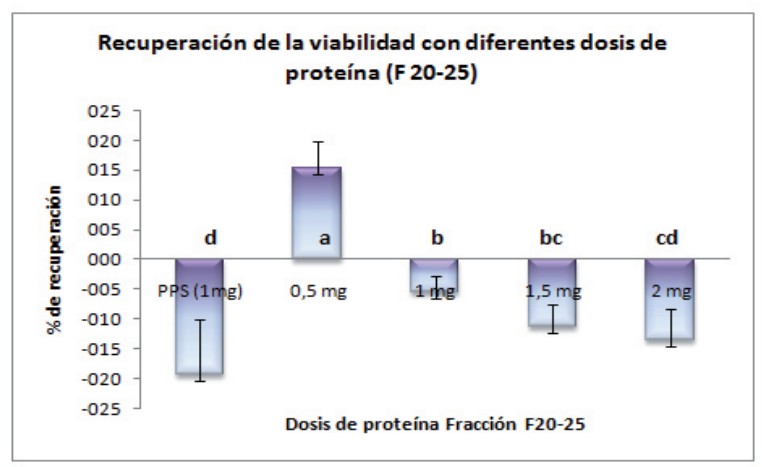

Figura 5. Porcentaje de recuperación de la viabilidad de la membrana espermática en espermatozoides, congelados con Bioxcell ${ }^{\circledR}$, descongelados e incubados con la fracción F21-25. El porcentaje de recuperación se evaluó mediante la fórmula $\left[\left(V_{p} 60-V_{c} 60\right) /(V w-V c 60)\right] \times 100$. 


\section{DISCUSIÓN}

El análisis electroforético unidimensional evidenció dos bandas de 14 y $16 \mathrm{kDa}$, que se encuentran en las fracciones 21 a 25 . La cantidad relativa de cada banda (entre 26 y $22 \%$ ) y su aparición en todas las fracciones, demostrada en la electroforesis unidimensional, indicó que estas proteínas son las más abundantes dentro del PS. En este sentido se ha evidenciado que las proteínas BSP, son las más abundantes en el PS bovino $(2,19,22,23)$. La concentración de estas proteínas en el PS está entre 20 y $40 \mathrm{mg} / \mathrm{ml}$, lo que corresponde a una concentración de entre el 30 y el $60 \%$ de las proteínas totales del PS.

La banda de $14 \mathrm{kDa}$ coincide con el peso molecular de las proteínas PDC 109 y aunque dicha banda puede contener más proteínas de peso molecular igual o cercano, es muy posible que el concentrado de fracciones 21 a 25 obtenido en la presente investigación, contenga cierta cantidad de estas proteínas. El análisis electroforético bidimensional evidenció la presencia de varios puntos, dentro de los cuales podrían estar las proteínas PDC-109; sin embargo es necesario llevar a cabo más estudios encaminados a la identificación de estos puntos.

Por otro lado, Barrios et al (1) lograron separar fracciones similares a partir de PS ovino. En las fracciones que separaron se encontraron dos bandas de proteína de 14 y $20 \mathrm{kDa}$ en lo que denominaron fracción 6 . Estas dos bandas representaron cerca del $70 \%$ de las proteínas totales del PS ovino. La fracción 6 se seleccionó para ser usada en pruebas de reversión de daño en membrana de spz sometidos a choque térmico por bajas temperaturas.

La adición de la fracción cromatográfica 21-25 evidenció que existe un aumento en la viabilidad post incubación de alrededor del $20 \%$ cuando se usa entre 1 y $1.5 \mathrm{mg}$ de la fracción proteica por cada millón de spz descongelados. Esta dosis es adecuada cuando se usa un crioprotector con yema de huevo. Además, se observó un aumento similar con una dosis menor de proteína de las fracciones $21-25$ (0.5 mg/millón de spz) cuando se usa medio comercial Bioxcell ${ }^{\circledR}$ en la congelación. Esto último sugiere la posibilidad de que el medio comercial contenga algún componente que pueda tener interacción con las proteínas contenidas en las fracciones 21-25.

Por otro lado, el tratamiento con el conjunto de proteínas del PS, evidenció un efecto contrario, disminuyendo la viabilidad del semen luego de ser incubado con ellas. Asimismo se ha demostrado que el PS completo en exceso tiene un efecto nocivo para la viabilidad espermática (22). Por su parte, Barrios et al (1), describió, en ovinos, que la adición del conjunto de proteínas de PS, aunque no disminuye la viabilidad después de someter los spz a choque térmico por frío, tiene un efecto de recuperación de la viabilidad menor que el ejercido por la adición de la fracción 6 (con proteínas de 14 y $20 \mathrm{kDa}$ ), y que la adición de fracciones de PS, que contienen proteínas con pesos moleculares superiores a $60 \mathrm{kDa}$, no tiene mayor efecto en la recuperación de la viabilidad del semen ovino.

Los resultados de la presente investigación sugieren la posibilidad de que sean las proteínas de bajo peso molecular presentes en la fracción 21-25 del PS, las que intervienen en la recuperación de la membrana del spz bovino sometido a criopreservación.

Cuando en el análisis de los datos se tiene en cuenta el descenso de la viabilidad desde el momento de la recogida de la muestra, se logra apreciar una recuperación de la viabilidad espermática post incubación de alrededor de $15 \%$, con una dosis de $0.5 \mathrm{mg}$ de la fracción 21-25 por millón de spz, previamente congelados en medio Bioxcell ${ }^{\circledR}$. Dosis más altas parecen no tener mayor efecto, e incluso algunas son nocivas para la viabilidad post incubación.

El trabajo reportado por Barrios et al (1) para semen ovino, indica que la dosis mínima para obtener un efecto de reversión significativo $(p<0.05)$, corresponde a $0.5 \mathrm{mg} / 10^{6} \mathrm{spz}$ de la denominada "Fracción 6". Sin embargo, observaron un efecto reparador dosis dependiente hasta $2.5 \mathrm{mg} / 10^{6} \mathrm{spz}$. Es posible que el efecto negativo evidenciado en la presente investigación sea debido a una interferencia del medio comercial empleado para la congelación del semen.

Se ha descrito que el proceso de congelación - descongelación tiene un efecto negativo en la integridad y la funcionalidad de la membrana espermática. Esta membrana es fundamental para el metabolismo espermático y para que el spz lleve a cabo varios procesos involucrados en la fecundación (24). Se ha demostrado que el PS puede suprimir y revertir la capacitación(decapacitar spz previamente capacitados) (12). Por tanto, los presentes resultados podrían deberse al efecto de adsorción a la membrana espermática que presentan proteínas específicas del PS. Proteínas como las BSP (posiblemente contenidas en la fracción 21-25), poseen la capacidad de adsorción a la membrana plasmática por su interacción con los fosfolípidos de la misma $(9,19,22,23)$, lo que permite explicar en parte, 
el efecto de recuperación de la viabilidad espermática evidenciada por la fracción. El efecto decapacitante de éstas proteínas se encuentra asociado a su cantidad. Es posible que dosis más altas de la fracción, capaciten a los spz en lugar de inhibir su capacitación, lo que podría explicar el efecto negativo observado cuando se adicionaron dosis de la fracción, superiores a $0.5 \mathrm{mg} / 10^{6} \mathrm{spz}$. De esta manera, aunque existe recuperación de la viabilidad espermática, al adicionar proteínas semi-purificadas contenidas en la fracción 21-25, el efecto de recuperación post incubación, depende también de la cantidad adicionada y del medio de congelación empleado.

El medio Bioxcell ${ }^{\circledR}$ es un crioprotector comercial fabricado a base de lecitina (fosfatidilcolina) de soya. La fosfatidilcolina se compone de ácidos grasos poliinsaturados de 18 carbonos y colina; este compuesto está presente en las bicapas lipídicas de las membranas celulares. Se ha determinado que las proteínas BSP A1/ A2 interactúan con la colina de los fosfolípidos presentes en la membrana espermática durante la eyaculación (9). Dado que las proteínas BSP estimulan la salida de fosfolípidos, es posible que la fracción 21-25, añadida a spz descongelados (criopreservados con Bioxcell ${ }^{\circledR}$ ), presente una fuerte interacción con el medio de criopreservación, razón por la cual la adición de la fracción en cantidades superiores a 0.5 $\mathrm{mg} / 10^{6} \mathrm{spz}$, posiblemente desencadene procesos de capacitación espermática, disminuyendo el porcentaje de spz viables.

Sin embargo, cuando se empleó el medio citrato-fructosa-yema de huevo, la cantidad de la fracción que incrementó los porcentajes de viabilidad espermática fue mayor que cuando se empleó Bioxcell ${ }^{\odot}$ en la congelación. A diferencia del Bioxcell ${ }^{\circ}$, la yema de huevo contiene lipoproteínas de baja densidad (LDL) además, de fosfatidilcolina. En este sentido, Manjunath et al (24) demostraron que el efecto protector de la yema de huevo se debe a la interacción entre las proteínas BSP y las LDL de la yema. El hecho de que la cantidad de proteínas que resultó eficaz cuando los spz se congelaron con el medio que contenía yema de huevo sea mayor podría deberse a la interacción de las LDL presentes en la yema de huevo con las proteínas adicionadas en la fracción. Estos resultados abren camino a nuevas investigaciones que permitan ratificar el efecto de las proteínas del plasma seminal sobre espermatozoides descongelados.

Los datos obtenidos permiten concluir que la adición de las fracciones 21-25, de PS que contienen proteínas de bajo peso molecular, revierte en parte el efecto deletéreo ocasionado en la membrana espermática, por la criopreservación. La incubación de spz, con las fracciones proteicas 21-25 incrementó la viabilidad espermática post descongelación de eyaculados criopreservados en diferentes medios. Este incremento en el porcentaje de spz viables post incubación, varió dependiendo de la cantidad de proteína de la fracción 21-25 utilizada en la incubación. Se evidenció una disminución en la viabilidad post incubación, cuando los spz congelados en medio comercial, se incubaron con dosis mayores a $0.5 \mathrm{mg} / 10^{6}$ spz de la fracción proteica 21-25.

Los resultados de este trabajo, sugieren la realización de nuevas investigaciones, que involucren el uso de proteínas extraídas y purificadas del PS en los protocolos de criopreservación, con el fin de aumentar las tasas de fertilidad del semen críopreservado.

\section{Agradecimientos}

Este trabajo hizo parte del proyecto "Desarrollo de alternativas para mejorar la viabilidad del semen en los procesos de criopreservación de toros Sanmartinero y Cebú" financiado por el Ministerio de Agricultura, IICA y FEDEGAN. Fue posible gracias a Eliana Neira, Gustavo Quijano, Samuel Correa, Guillermo Onofre y Yolmar Zorro.

\section{REFERENCIAS}

1. Barrios B, Perez PE, Gallego M. Seminal plasma proteins revert the cold-shock damage on ram sperm membrane. Biol Reprod 2000; 63:1531-1537.

2. Moura A, Hasan K. Identification of proteins in accessory sex gland fluid associated with fertility indexes of dairy bulls. J Androl 2006; 27(2):201-212.
3. Watson PF. Cooling of spermatozoa and fertility capacity. Reprod Domest Anim 1999; 31:135-40.

4. Moussa M, Matinet V, Trimeche A, Tainturier D, Anton M. Low density lipoproteins extracted from hen egg yolk by an easy method: cryoprotective effect on frozenthawed bull semen. Theriogenology 2002; 57:1695-706. 
5. Gil J, Rodiguez-Irazoqui M, Lundeheim $\mathrm{N}$, Soderquist L, Rodriguez-Martinez $\mathrm{H}$. Fertility of ram semen frozen in Bioexcell and used for cervical artificial insemination. Theriogenology 2003; 59:1157-70.

6. Forouzanfar M, Sharafi SM, Hosseini S, Ostadhosseini M, Hajian L, Hosseini P et al. In vitro comparison of egg yolk-based and soybean lecithin-based extenders for cryopreservation of ram semen. Theriogenology 2010; 73:480-487.

7. Bousseau S, Brillard JP, Guienne M, Guerin $B$, Camus A, Lechat M. Comparison of bacteriological qualities of various egg yolk sources and the in vitro and in vivo fertilizing potential of bovine semen frozen in egg yolk or lecithin-based diluents. Theriogenology 1998; 50:699-706.

8. Gwathmey T M. PDC-109 (BSP-A1/A2) promotes bull sperm binding to oviductal epithelium in vitro and may be involved in forming the oviductal sperm reservoir. Biol Reprod 2003; 69:809-815.

9. Manjunath P, Lefevbre J, Wright W. 2009. New nomenclature for mammalian BSP genes. Biol Reprod 2009; 80:394-397.

10. Barrios B, Fernández-Juan M, Muiño-Blanco T, Cebrián-Pérez J.A. Immunocytochemical localization and biochemical characterization of two seminal plasma proteins which protect ram spermatozoa against coldshock. J Androl 2005; 26:539-549.

11. Desnoyers L, Therien I, Manjunath, P. Characterization of the major proteins of bovine seminal fluid by two dimensional polyacrilamide gel electrophoresis. Mol Reprod Dev 1994; 37:425-435.

12. Cross NL. Multiple effects of seminal plasma on the acrosome reaction of human sperm. Mol Reprod Dev 1993; 35:316-323.

13. Fernández-Juan $M$, Gallego $M$, Barrios $B$, Osada J, Cebrián-Pérez J.A, Muiño-Blanco T. Immunohistochemical localization of spermpreserving proteins in the ram reproductive tract. J Androl 2006; 27:588-595.

14. Perez-Pe R, Cebrián-Perez J, Muiño-Blanco T. Semen plasma proteins prevent cold-shock membrane damage to ram spermatozoa. Theriogenology 2000; 56:425-434.
15. Colas $C$, Junquera $C$, Perez-Pe R, CebriánPérez JA, Muiño-Blanco T. Ultrastructural study of the ability of semnial plasma proteins to protect ram spermatozoa against cold-shock. Microsc Res Tech 2009; 72:566-572.

16. Harrison RA, Vickers S. Use of fluorescent probes to assess membrane integrity in mammalian spermatozoa. J Reprod Fertil $1990 ; 88: 342-353$.

17. Laemmli UK. Cleavage of structural proteins during the assembly of the head of bacteriophage T4. Nature 1970; 227:680-685.

18. Cardozo J.A, Fernández-Juan M, Forcada F, Abecia, A, Muino-Blanco T. CebrianPérez J. 2006. Monthly variations in ovine seminal plasma proteins analyzed by two dimensional polyacrylamide gel electrophoresis. Theriogenology 2006; 66:841-850.

19. Therien I, Moreau R, Manjunath P. Bovine seminal plasma phosphplipids binding proteins stimulate phospholipids efflux from epididymal sperm. Biol Reprod 1999; 61:590-598.

20. Swamy M. Interaction of bovine seminal plasma proteins with model membranes and sperm plasma membranes. Cur Sci 2004; 87:103-211.

21. Rota A, Penzo N, Vicenti L. Hypoosmotic swelling (HOS) as a screening assay for testing in vitro fertility of bovine spermatozoa. Theriogenology 2000; 53:1415-1420.

22. Souza C, Moura A, Killian G. 2008. Binding patterns of bovine seminal plasma proteins $\mathrm{A} 1 / \mathrm{A} 2,30 \mathrm{kDa}$ and osteopontin on ejaculated sperm before and after incubation with isthmic and ampullary oviductal fluid. Anim Reprod Sci 2008; 105:72-89.

23. Moura A, Chapman D, Killian A. 2007 comprehensive proteomic analysis of the accessory sex gland fluid from mature Holstein bulls. Anim Reprod Sci 2008; 98:169-188.

24. Manjunath $\mathrm{P}$, Therien, I. Role of seminal plasma phospholipids binding proteins in sperm membrane lipids modification that occurs during capacitation. J Reprod Immunol 2002; 53:109-119. 